\title{
The 21st Century Learning Model: Electronic Tutelage Realized
}

\author{
Kathryn A. Marold, Ph.D. \\ Metropolitan State College of Denver, \\ Denver, CO, USA
}

\section{maroldk@mscd.edu \\ Executive Summary}

The $21^{\text {st }}$ century learning model of electronic tutelage is explained. With the movement of the personal computer into the "everyday" of our existence, the underlying theory of electronic tutelage is explained and supported. Electronic tutelage refers to the use of computers to learn new concepts, rather than using the human teacher-learner interaction. The changes in the delivery of IT education are a reflection of the technological changes in our society as a whole. The delivery of education by use of computer as a complement, or even a substitute for, the human tutor is the essence of electronic tutelage. The move from oral to print-dependent to electronic noesis was evolutionary. Electronic tutelage is an electronic "way of knowing." The author cites research from different disciplines that support the proposition that electronic tutelage is a reality in our modern IT education, and that it is largely successful. There are three main arenas where electronic tutelage is utilized-in the computer enhanced "smart classrooms", in hands-on computer laboratories, and in Web-based course offerings. Citing the results of two earlier research projects, a comparison of student ability to apply theory is related to the delivery mode-Web-based or classroom.

There is evidence that students in Web delivered courses cannot apply concepts learned as well as their counterparts in the classroom environment. The interactive "smart" classroom, where all students have a computer for all class meetings may be the most successful arena of electronic tutelage yet developed. A student satisfaction survey showed acceptance and approval of the smart classroom technique. Students enjoyed learning this way, and felt they earned better grades because of the technology-laden environment. The hands on labs that were implemented in the 1980 s as part of IT education continue to be used; they are, however, self-paced and private. The smart classroom is social and directed, rather than selfpaced.

The theory of extension transference- using a computer as an extension of the biological self - is supported. The conclusion is that after fifty years, computers are finally integrated almost seamlessly into our IT education.

Keywords: electronic tutelage, electronic noetic, extension transference, ATAP, smart classrooms, Web-based courses, CBT, WBT, participatory

Material published as part of this journal, either on-line or in print, is copyrighted by the publisher of the Journal of Information Technology Education. Permission to make digital or paper copy of part or all of these works for personal or classroom use is granted without fee provided that the copies are not made or distributed for profit or commercial advantage AND that copies 1) bear this notice in full and 2) give the full citation on the first page. It is permissible to abstract these works so long as credit is given. To copy in all other cases or to republish or to post on a server or to redistribute to lists requires specific permission and payment of a fee. Contact Editor@ JITE.org to request redistribution permission.

\section{Introduction}

The personal computer is the "universal tool" of the twenty-first century-born in the last century, but reaching maturation in our time. All new technologies are used in an "old", more familiar way when they are first introduced. It requires a period of adjustment for us to realize their potential and use them in the "new" way that they are truly intended (Ong, 1982.) For the last two decades of the twentieth century we became accustomed to the 


\section{Electronic Tutelage}

capabilities of the personal computer. Today, we use the computer--desktop to personal digital assistant-for everything from document preparation, to communication and information retrieval. We use it to research, plan, and produce. Its ubiquitous presence in our lives merits its place as the all-purpose "vege-matic" of our culture. It is natural, then, that we have adapted the personal computer to our educational needs.

The learning model of the $21^{\text {st }}$ century uses the computer as the conduit for teaching and learning. The state of teaching information systems today, after the influence of technology and the saturation of computers in our lives, is one of electronic tutelage. Electronic tutelage refers to the use of computers to learn new concepts, rather than using the human teacher-learner interaction (Marold, 1994.) It consists of teaching with the assistance, or sometimes the total substitution, of computer for human teacher. We have by this century incorporated computers into the learning process so that they are no longer an obstacle, but are an integral delivery component in IT education.

In our century, we have reached the stage of extension transference that Edward Hall predicted in 1973. Extension transference theory holds that the computer serves as a "prosthesis"—almost a biological extension of our physical beings. We use it with much the same ease as we use one of our natural limbs. Just as the bicycle wheel serves as an extension of our legs to propel us forward, the computer extends the bounds of our ability to learn (McLuhan, 1964). The PC, however, is not the end; it is the means to the end. It is our tool for mastery of Information Technology concepts. This article suggests that the new learning model of the $21^{\text {st }}$ century Information Technology education is electronic tutelage. That model has far-reaching effects-both for the teachers and the learners. In the $21^{\text {st }}$ century, the probe that Marshall McLuhan introduced more than forty-five years ago_ — "the medium is the message"—has come to fruition.

\section{The Changing Model of Education Delivery}

The university teaching model that was developed in the fifteenth century and persisted for over 500 years relied heavily on the new development of printing (Havelock, 1976.) The printing press was the new technology of its century; it allowed a new teaching model to be developed by the end of the $15^{\text {th }}$ century that included lecturer and audience, passive learning and more private reading and introspection. It replaced the Oral Model, a memory-intensive open Forum and Query Model that Aristotle, Socrates, and Plato championed. In turn, five centuries later not only did the electronic medium spawn information technology as we know it today; it also resulted in yet another model of learning: electronic tutelage is at the heart of the new model. Ong realized this as early as 1967, when he introduced the electronic noetic--his adaptation of the Greek noesis, or way of knowing. The electronic noetic has resulted in a true shift in the way we deliver IT education today. Embracing the potential of the electronic noetic characterizes information technology education in this century.

Certainly, the profile of the information technology learner has changed. The college student studying information systems today is far different from the EDP (electronic data processing) student of the 1970s. It follows, then, that the way we deliver education to the IT student in the $21^{\text {st }}$ century should also change. This article supports the notion that computers have become such an integral tool in the "everyday" of our lives that they have affected the very way we teach and learn information systems (Bausinger, 1984.)

\section{Electronic Tutelage Arenas}

At the forefront of this change in the learning model are several conditions: computers in the classrooms, hands-on experience with information systems of all types, and Web-augmented or Webdelivered courses. Electronic tutelage occurs in all of these arenas. In the traditional classroom, PowerPoint ${ }^{\circledR}$ slides, Web access, and "live" demonstrations have supplanted "chalk 'n talk." Smart classrooms and fully equipped meeting areas bring information systems concepts alive for students. Campus computer laboratories give all students a computer station where they learn by interfacing with a program 
rather than an instructor-both in a structured and unstructured learning environment. And the newest development in personal computing - the Web-allows Internet delivered and Internet augmented classes that give students a global interactive multimedia environment with which to learn. These three computing conditions have transformed information technology education.

\section{Literature Review}

To better understand changes in technology, we employ McLuhan's "rear view mirror" (1964.) There is a wealth of research transcending all disciplines to give us a foundation from which to understand electronic learning. Examining learning in the oral and print modes help us better understand the shift to the electronic mode; reviewing the latest research on Web-based learning lends credence to adoption of electronic tutelage as the new learning model.

\section{Oral and Print Noetic Scholars}

The rear view mirror approach that Marshall McLuhan explains is one of hindsight. He held that in order to understand a new technology, we must look to the preceding one for insight into the change taking place. We do not have a clear picture of a new technology until we examine the preceding one. Ong's primary oral culture was distinguished by no writing at all. The spoken word was the only way to learn; the learning mode was auditory, supplemented only by gestures and verbomotor traits (1982.) The spoken word with its temporary, transitory nature relied on human memory to catalog and pass on knowledge. Print did not exist and writing was restricted to painstakingly hand-rendered manuscripts that could only be read by literate scribes. The limitations of that educational model (though there are many benefits as well) are obvious. Research on the print noetic contrasts the two environmentsprimary oral cultures and secondary oral cultures (Havelock, 1976; Olson and Torrance, 1991.) With secondary oral cultures, the oral/aural mode continued, but was combined with writing. When knowledge could be set down and eventually printed, the learning model changed dramatically. Writing and print were the technologies of their times; they spawned a new teaching and learning model. There would not be such a dramatic change again until electronic processing and storage propelled us forward again. McLuhan first named the latter noetic the "Electric Age" when mass media and television transformed our lives, but history records this whole movement from radio, to film and television, and to computing as the Information Age. It was the Information Age at the end of the $20^{\text {th }}$ century that we now look to in order to solidify our thoughts on Information Technology Education in the $21^{\text {st }}$ century. It is this "rear view mirror" that allows us to see where we are by examining where we have been.

\section{Psychologists and Educators}

From eighteenth and nineteenth century psychologists like Vygotsky, Piaget, Luria, and Guilford to pioneer researchers of electronic mode such as McLuhan, Ong and Levi-Strauss, a clearer path to a model of electronic learning evolved. Pioneer education theorists provided the groundwork for learning processes. Cognitive psychology and human information system processing owe a large debt to these early scholars of intelligence and learning. When Turkle's research brought her to school age children whose first experience with computers transformed their learning, she looked to the earlier research of Dewey, Montessori, and even Piaget who first championed "think and do" or "hands-on learning." When she called computers "the second self" she relied on Levi-Strauss' "tinkerers and planners." She concludes that computers change the human spirit and become almost a second entity within our minds (1984.) Seymour Papert's early research on the effect of computers on children's learning habits, and his Logo programming language that allowed children to learn mathematical principles by manipulating a turtle showcased electronic tutelage (1980.) All of us who tout the advantages of JIT (Just In Time) ATAP (Any Time Any Place) learning on the Web echo Shank's long-held theories of true learning occurring 


\section{Electronic Tutelage}

precisely when we need to know (1995.) The research of psychologists and educators give credence to modern learning models, including that of electronic tutelage.

\section{Early Research on Computer-based Learning}

The model of electronic tutelage is rooted in the early research that was done when computer aided (or assisted) instruction (CAI) began in the 1980's. Although early computer aided learning was entirely text-based and linear, research proved that it could be successful. Brandon Hall found that computer based training, whether text based or multimedia resulted in equal or higher quality of learning over traditional instruction (1995.) As the text-based CAI programs gave away to more multimedia CBT (computer based training) programs with other media--graphics, sound, animation-- and as we become accustomed to using computers, the success rate and efficacy of electronic tutelage improved. In one of the earliest studies on CBTs in academic and business environments, Barker found that CBTs reduced instruction time, were easier for employers to monitor, and resulted in better content retention (1989.) The computer as tutor had gained acceptance. It was not both possible and practical to replace the traditional classroom headed by an instructor, however, until the Web become part of our everyday lives. Research on computer "enhanced" learning still concentrated on electronic tutelage as a complement, or addition to, course content. Self-paced tutorials and lab manuals were part of the instruction, not the only means of delivery. There was usually a dedicated physical location and a human facilitator. When the World Wide Web was introduced and Internet access became common, WBTs--Web Based Training--put the now familiar computer based training onto the Web interface. Computer and user now interacted as a dyad, without the human intervention of a classroom instructor.

\section{Modern Computer Media Scholars}

The modern media scholars who transcend the stages of electronic tutelage offer the most valuable research. These individuals have been, and many continue to be, intensely involved in the move toward the substitution of computer for tutor. Nicolas Negroponte established the MIT Media Lab in the mid 1970s, and has closely followed the evolution of computing in our lives. In 1995, he noted in his seminal book, Being Digital, that "Computing is not about computers any more. It is about living." He, Marvin Minsky, Seymour Papert, and other early AI (artificial intelligence) researchers laid the ground for many of the advancements in human computer interfaces. Brandon Hall's findings on multimedia corporate training programs (1995) are now being mirrored within the traditional educational arena as well. The conclusions of the modern computer media scholars serve as the "rear view mirror" for the latest investigations into electronic tutelage - the research on Web-based learning.

Research on Web-based learning seals the argument for proposing that the $21^{\text {st }}$ century model of IT education is one of electronic tutelage. As testimony to the acceptance of electronic tutelage, educational institutions everywhere have invested heavily in Web courses for credit. Many of these courses are traditional broad general studies undergraduate courses, but many are also Information Systems courses at the bachelor's, master's and doctorate level in business schools. Entire degrees in Information Systems are offered online, via the Web. These independent degrees have as much validity as ones earned in the traditional classroom. (Most college transcripts do not distinguish between credits earned in the traditional classroom and those earned by taking a Web course.) Recent research into success of Web delivered courses range from comparing differences in mastery of concepts (Schulman 1999; Soloway, 1995) to the social aspects of learning in isolation (McCloskey, 1998.) Research on the success of Web based learning indicates, for the most part, that Internet courses and Web augmented courses are just as successful a mode of learning as classroom courses. Repeatedly, no significant differences in final grades between classroom sections and Web sections are found. (McCloskey, 1998; Marold, 2000.) Research shown here challenges some of the earlier findings, however. 


\section{Elaboration of the Electronic Tutelage Model}

\section{Background and Definitions}

Education, whether it be formal or informal, first requires introducing the learner to the unfamiliarimparting concepts so that the learner may understand something previously foreign, and may develop an understanding, and be able to expand on the idea. These higher mental processes Vygotsky referred to as "scientific concepts"—concepts beyond mere naming or identifying concepts (Vygotksy, 1987.) Whether the cognitive process is referred to as "mentation" (Dance), "higher mental processes" (Luria), "complex cognition"(Wolf), "cerebration" (Salomon), the "cognition operation of the structure of intelligence" (Guilford), "human information processing" (Minsky), or any other of the many terms that were introduced as cognitive science and the field of artificial intelligence developed (Chomsky), they all refer to realizing and understanding new deeper concepts that were not known before. In hundreds of years of studying cognitive development and learning theories, we have found that to begin the learning process, something outside of the individual needs to intervene to trigger the initial cognitive processes, and conditions to expand on seminal ideas must be present. As tradition sees it, we have referred to the outside forces as the tutor.

We have also long known that physical proximity of tutor and learner is not necessary: we have had forms of distance education for many years. We also know that the tutor doesn't necessarily have to be a trained teacher, or even a physical human being. CAI, CBTs, and the Web with its graphical browsers that are now a standard interface, are evidence. The promise of electronic tutelage-substituting human tutor with electronic ones-can be a universal alternative to the older teaching and learning models.

\section{Advantages and Disadvantages}

The $21^{\text {st }}$ century model for delivery of Information Technology education is advantageous in several ways. The system of representation for electronic content is moving quickly toward multimedia. That is, text is only part of the symbol set. Graphics, sound, animation, and even full-motion video are combined to deliver a richer content. The delivery organization is often nonlinear; the content can be hyperlinked, in a link by association fashion, rather than the sequential or hierarchical manner that characterized the teaching model of the last century. The learner can often access this richer content in any order he/she chooses, at any time that is appropriate. This is the theory underlying ATAP JIT (Any Time Any Place, Just in Time) learning that is so popular today. With nonlinear organization and computerized delivery, access to course material can truly be individual; the learner receives the tutoring when he/she most needs it, in the sequence and quantity for which he/she is most ready. This is a marked advantage over the delivery of any type of education in last century.

Braun and Crable researched the "paperless classroom", finding that in reality since students printed out the material themselves--sometimes multiple times--it didn't save much paper, but the classes benefited from electronic delivery of notes, syllabi, class handouts, and so forth (1999.) The advantage of having dynamic Web pages on campus network drives where students can access material and submit assignments is obvious. Access is universal. Changes in information systems developments, hardware or software releases, project progress, and so forth can be reflected immediately. Schedule changes and content changes are much easier.

An added advantage of the electronic tutelage model is the aesthetics of content delivery. A smart classroom where images and text can be neatly displayed for all to see clearly is a tremendous improvement over the teaching model of the last century. Difficulty hearing an instructor whose back is turned to the class while writing indecipherable notes on a blackboard much distant from the student is a learning impediment of the past. The electronic tutelage learning environment within smart classrooms is much improved from the "chalk and talk" model of the last century. PowerPoint $®$ slides, even ones with plain text, are much improved over transparencies and handwritten notes. Formulas and flowcharts typed within software at the moment of delivery teach not only the concept, but also the tool at the same time. 


\section{Electronic Tutelage}

Demonstrations of actual programming constructs within a language editor, or actual hands-on experience by all class members in "smart" lecture halls equipped with computers gives the learner a real advantage over simply observing the instructor's demonstration.

A great advantage of the electronic tutelage model is that the learner is actively engaged in the learning process. The passive learner that sometimes characterized the learner with the educational model of the last century is no longer appropriate with the $21^{\text {st }}$ century model. Electronic tutelage is above all participatory; learning is not successful unless the learner is actively engaged in the process. If there is no interactivity, there is no learning. This puts the burden for learning not on the tutor, but on the learner. (In reality, both the teaching models of the oral noetic and the print noetic required participation by the learner for true full learning to take place, but it was not quite so obvious. Educators naively claimed that if the tutor was good enough, the learner would surely synthesize the content.) Learning may be directed, but the learner must actively participate for it to be successful.

The electronic tutelage model is not without disadvantages. If learning is individual and self-paced, the group discovery that characterizes the ideal classroom situation is lost. There is a loss of the powerful collaborative aspect of group learning. What is more, with electronic tutelage often the sequence and pace is an individual choice; the emphasis an instructor places on content can therefore be lost. With freedom comes responsibility to master content with the same emphasis the tutor places on it. Because the learner does not know the content, prioritizing the most important aspects is difficult, even though there may be visual clues such as placement on a Web page, size of area devoted to the subject, and so forth. Another disadvantage that electronic tutelage has with any electronic materials is that content is not easily markable; it cannot easily be reordered or rechunked from its original state. Lastly, it is not very portable, despite laptop and hand-held computers. These disadvantages are yet to be overcome; as the model matures, we will no doubt find means of dealing with these challenges. They are, nevertheless, admitted impediments to assimilating the electronic tutelage model into the "everyday" of our learning.

\section{Ways to Implement Electronic Tutelage}

The "trigger" to new learning can be delivered one of several ways. As noted, it can be within the computer augmented traditional classroom; it can be in a hands-on experiential computer laboratory, or even by the student interacting individually with content on the World Wide Web. Electronic tutelage can be achieved in groups or individually. It can be at pre-assigned class meetings or by the Web at any time, any place (ATAP), precisely when the mind is receptive to learning. The variety of scenarios for electronic tutelage is part of its strength. The new $21^{\text {st }}$ century model of delivering information technology education via computer and the Internet has changed business education forever.

\section{Computers in the classrooms}

Using computers to supplement and redesign the classroom experience is the arena all content areas can benefit from-whether it is Information Technology education or any other type of education. This author's experiments with delivering the Visual Basic programming classes in a new "smart classroom" for Business School students at Metropolitan State College of Denver not only improved the aesthetics of delivery, it resulted in more student satisfaction with course delivery and perceived improvement in learning (Marold and Socash, 2002.).

The class components were distinguished by:

- An active, hyperlinked Course Syllabus Web page on the campus server

- A system of in-class objectives and notetaking process using word processor instead of manual notebooks

- Series of PowerPoint ${ }^{\circledR}$ slides that both instructors and students used for theory presentation

- Series of programming exercises to practice the VB coding process

- Supervised self-paced lab sessions held right in the smart classroom 
- Periodic quizzes submitted via email, to prepare for class exams

- In-classroom major exams using computer stations in the lecture hall

The students were required to actively participate in class sessions while the instructors guided them through the material. This was not a self-paced lab situation, but instead, participatory class meetings where material for the week was presented and discussed, and students engaged in activities appropriate to the week's lesson. It differed from some of the more interactive traditional classrooms only in that pencil did not touch paper, and chalk/dry marker did not touch the chalkboard/whiteboard. Students saved their class notes and programming exercises on disk rather than in a notebook. Instructors projected the same material on the large overhead screen, formatted and enlarged for better communication with the class. It typified electronic tutelage of the first arena--as a supplement to the classroom. Students reported anecdotally that although the class meetings were much more intense, they felt the inclass demonstrations and activities resulted in better learning and better grades than they would have achieved in a traditional classroom (Marold and Socash, 2002.).

The interactivity resulting from properly-used, fully-equipped smart classrooms brings content to Information Technology learners with the learning style with which they are most comfortable (Hanson, 1993.) Even if hands-on laboratory sessions and Web courses were not a part of the academic environment, electronic tutelage could be a reality within the $21^{\text {st }}$ century educational model for the price of redesigned classrooms.

\section{Computers in the IT Labs: Hands-on experience systems}

Class lab sessions with common software programs have been a part of Information Technology curricula since the mid 1980's. What has been commonly become known as "productivity" portions of courses now occupies a percentage of almost every Information Systems course in schools everywhere. Teaching concepts along with the programs that are the tools for the production of information systems has been largely successful (Bowman, 1995.) This hands-on "learning by doing" is a valuable experience for Information Systems graduates, even when the productivity lessons are basically keystroke lessons and tutorials. It is an experience with application of theory that models what the graduate will do for a good portion of his/her work experience. This "bottom up" approach to learning fits well within the electronic tutelage model. From practice with the tool, the learner can gradually come to the concept of the previously unknown principle. By combining lecture sessions with laboratory sessions, the learner has exposure to top-down and bottom up methods, which increases the opportunity for understanding. This type of Information Technology education would not be possible without the pervasive presence of personal computers in our lives, and the ubiquitous campus computer labs.

\section{Web-augmented or Web-delivered courses}

Most theorists agree that one learns best when the new material becomes something one needs to know, and the closer the tutor is to the realization of need, the better the learning environment (Shank, 1995.) The Web wins on all counts here. The Web is a learning environment; content properly designed and delivered by a virtual tutor holds great promise.

Perhaps the most frequent occurrence of Web-based learning is what is commonly referred to as the "hybrid" course. Although the class physically meets a set number of times, the Web is used for a portion of the student learning. Presby reports that these courses are largely successful (2001.) Technically, the Web hybrid course uses the World Wide Web for any part of the course, regardless of the percentage; therefore almost every IT course today can qualify as a hybrid. However, hybrid courses where thirty per cent or more of the class work uses the Web, eliminating a physical class meeting is generally regarded as a hybrid course. A plan for hybrid delivery of the required School of Business beginning Information Systems course at a large metropolitan university promised to cut the required sections for its 650 students each semester from 23 sections to 6 , without cutting the personal attention and valuable lab experience (Marold and Fustos, 2001.) Students gain much of the material from the Web rather than 


\section{Electronic Tutelage}

from the master lecturer, and class meetings are cut from three hours each week to one classroom meeting and one lab meeting each week.

Totally Web-based courses are growing even faster than hybrid courses. This is where electronic tutelage is a total substitution for human tutelage. While attrition rates are still higher than classroom courses, these courses are a fixture at every institution of learning, and are embraced by students, faculty, and administrators alike. Although final grades are not significantly different, the author and colleagues have found differences in how the final grades were earned (Marold, 2002.)

\begin{tabular}{|c|c|c|c|c|}
\hline IT Course & Delivery (n) & Projects & Exams & Final Grade \\
\hline CMS 1010 & Classroom(73) & 92.4 & 73.5 & 83.7 \\
\hline Intro to Computers & Internet(54) & 92.4 & 78.2 & 86.7 \\
\hline & t-value & -0.02 & $-2.02^{2}$ & $-1.45^{3}$ \\
\hline CMS 2010 & Classroom(34) & 91.8 & 70.01 & 79.2 \\
\hline $\begin{array}{l}\text { Computer Applica- } \\
\text { tions forBusiness }\end{array}$ & Internet (42) & 90.3 & 77.5 & 81.7 \\
\hline & t-value & .57 & $-2.63^{1}$ & -0.98 \\
\hline CMS 3270 & Classroom (48) & 93.8 & 67.8 & 86.4 \\
\hline $\begin{array}{l}\text { Micro-based Soft- } \\
\text { ware }\end{array}$ & Internet(51) & 87.5 & 77.7 & 86.7 \\
\hline & t-value & $2.57^{1}$ & $-1.48^{3}$ & -0.16 \\
\hline
\end{tabular}

\section{Table I : Differences in Achievement and Performance (Marold, 2002)}

Table I shows the findings of a study of more than 300 students in three levels of IT courses. The ability to complete projects that require application of theory was significantly lower in the junior level course. Grades on projects submitted were used to measure ability to apply concepts learned.

Table I shows that a significant difference was found in ability to apply theory (performance) on the part of online students. While ability to apply theory and willingness to complete what some online students regard as 'busy work" is a point to which we must attend, nevertheless there was a difference in performance. At initial stages of the move to electronic tutelage, there are many variances: courses are being delivered in a new way, sometimes by academics who are not experts at instructional design; students are not as accustomed to electronic tutelage as the traditional teaching models; students who take online courses necessarily are self-selected. There are a number of complications when examining how well the Web courses are working when evaluating the electronic tutelage model.

In another attempt to evaluate how well the Web-based arena of electronic tutelage is working, a study of the ability to apply concepts rather than simply recognize them was conducted by Haga, Marold and Helms (2001.) This research centered precisely on application of theory, both in exams and project assignments. In this research only upper level courses were used. All courses at the 3000 level and above at Metropolitan State College of Denver are organized around at least the level 3 of Bloom's Learning Taxonomy(1956) which are best described by terms such as apply, relate, analyze rather than recognize or recall. The authors felt that by comparing the means of Internet and classroom sections of two courses, they might better measure the student ability to apply theory in the traditional learning model and the electronic tutelage model. The results of this study are shown in Table II. 


\begin{tabular}{|c|c|c|c|}
\hline Course & Delivery(n) & $\begin{array}{l}\text { Exams } \\
\text { Mean }\end{array}$ & $\begin{array}{l}\text { Projects } \\
\text { Mean }\end{array}$ \\
\hline CMS 3145 Visual Basic & Classroom (28) & 71.3 & 73.3 \\
\hline & Internet (18) & 69.0 & 72.7 \\
\hline & t-Test (p-value) & $-0.297(.77)$ & $-0.09(.93)$ \\
\hline CMS 3230 & Classroom (59) & 62.7 & 83.5 \\
\hline Telecommunication & Internet (50) & 64.2 & 60.8 \\
\hline Systems & t-Test (p-value) & $0.309(.758)$ & $-6.35(p<.001)$ \\
\hline
\end{tabular}

Table II: Student Application of Theory in Upper Level IT Courses (Haga, 2001)

The t-test results showed a significant difference in the ability of CMS3230 students to apply concepts. Both courses had the same instructors online and in the classroom. Both courses measured applied portions of three exams, and three required projects. The lack of an appropriate sample for the programming course and vastly different courses may have compromised the results in this study. The Visual Basic course was in its first semester online; the sample in both groups was not as well balanced as the researchers would have liked. While a great significance was not found, the researchers were alerted to potential problems with online courses. They also saw a profile of the online learner emerging (Haga, 2001.) Eventually, all learners will likely participate in the electronic tutelage model to some degree, and probably within the Web-based arena. However, at the present the profiles of the online learners are quite distinct; they are distinct from their classroom counterparts. These research projects furthered the findings on how to properly implement the electronic tutelage model in the Web-based arena.

Web courses differ greatly. Some are better than others. Some possess solid instructional design and acknowledged pedagogy; some do not. No firm standards have been established yet for Web courses, although there are a number of organizations dedicated to the task. The American Web-based Education Commission is dedicated to studying how to deliver Web education, and the LEAD program (Learning through Evaluation Adaptation and Dissemination) developed by the Western Interstate Commission for Higher Education evaluates online courses' effectiveness (www.wiche.org). This is established attempt to recognize the vast differences in Web courses, and how we might develop a set of "best practices" to improve the Web aspect of the electronic tutelage model.

Teaching via the Web is simply not the same as teaching in the traditional classroom. New technology dictates the development of new methods. The years that we spent trying to use the new technology in the old way, trying to equate classroom experience with Web experience have made us the wiser. With a decade of experience, we are now beginning to use the new technology, and the new delivery means-the Web--in the way it was intended (Burgstahler, 1997.) This last arena for electronic tutelage is the newest, and the one with which we are least skilled. The author, in conjunction with colleagues, continues to research the success of Web-based arena of electronic tutelage. Generally, the measurement of success of electronic tutelage in the Web-based arena shows acceptance of the new model of learning. The Web will eventually assume the same place within the tutors' and students' lives as the computer itself has.

In all three arenas, electronic tutelage is so pervasive that many claim it has resulted in a "reengineering" of the university (Tsichritzis, 1999.) The new electronic tutelage model promises a richer experience for all.

\section{Summary}

In summary, extension transference theory holds that a technology can become almost a biological extension of ourselves, to make our lives easier. Computers have made such inroads into our daily lives 


\section{Electronic Tutelage}

that electronic tutelage does not seem as unfamiliar as it might once have seemed. We use computers as a daily tool for many aspects of our existence. The participatory nature of interacting with computers even hints at the earliest formal education, before the chalk 'n talk university model evolved-when the learner was not an audience, but an active participant. With the electronic tutelage that is now available, the information technology education model can change from "learning about" to "experiencing." There will always be a need for professional assessment and personal face-to-face contact with learners, but electronic tutelage can offer an unprecedented interactive personal learning opportunity. The arenas of the classroom, the computer lab, and Web courses allow for a new type of learning, and the personal computer is the tutor that provides it. The reengineering of the university in truth combines the old with the new, so that a stronger model results from the amalgamation of the traditional model and electronic tutelage model.

\section{References}

Barker, P. (1989.) Multimedia Computer Assisted Learning. NY. Kogan Page.

Bausinger. H. (1984.) Media Technology and Daily Life. Media, Culture and Society. 6: 4. 343-351.

Bloom. B.S., et al. (1956.) Taxonomy of Educational Objectives. Handbook I: The Cognitive Domain. NY. David McKay.

Bowman, B.J. et al.(1995.) Teaching End-User Applications with Computer Based Training: Theory and an Empirical Investigation. Journal of End User computing. 7:2. 12-17.

Braun, G. and E. Crable. (1999.) Student Perceptions of the Paperless Classroom. Proceedings of the Annual conference of International Business School Computing Association. Georgia Tech University. Atlanta, GA. July 18-21.

Burgstahler, S. (1997.) Teaching on the Net: what's the Difference? T.H.E. Journal. 24:9. 61-64.

Chomsky, N. (1968.) Language and Mind. NY. Harcourt, Brace and World.

Dance, F.E.X. (1979.) An Acoustic Trigger to Conceptualization. Health Communications and Informatics. 5:1. 203-213.

Guilford, J.P. (1967.) The Nature of Human Intelligence. McGraw-Hill. NY.

Haga, W. , K. Marold and S. Helms. (2001.) Round 2 of Online Learning: Are Web Courses Really Working. Proceedings from IBSCA Annual Conference. Providence, R.I. July, 2001.

Hall, B. (1995.)Return on the Investment and Multimedia Training. White Paper for Multimedia Training Newsletter. Sunnyvale, CA.

Hall. E. (1973.) The Silent Language. Garden City, NY. Anchor Doubleday Press.

Hanson, R. and J. Freeman. (1993.) Learning Style Differences of Management and Computer Information Systems Students. Proceedings of the Mountain and Plains Management Conference. Cedar City, IA. 7-9.

Havelock, E. (1976.) Origins of Western Literacy. Toronto. Ontario Institute for Studies in Education..)

Levi-Strauss, C. (1968.) The Savage Mind. Chicago, IL. University of Chicago Press.

Luria, A. and F.I. Yudovich. (1959.) Speech and the Development of Mental Processes in the Child. Translation by J. Simon. London. Staples Press.

Marold, K. (1994.) Constituent Elements of the Electronic Noetic. Ph.D. Dissertation. University of Denver. Denver, CO.

Marold, K. and G. Larsen and A. Moreno. (2000.) Web-Based Learning :Is It Working? Challenges of Information Technology Management in the $21^{\text {st }}$ Century. Idea Group Publishing. 350-353.

Marold, K. and J. Fustos. (2001.) Handling the Computer Literacy Requirement for Undergraduate Business Schools: A New Model for the New Millenium. Proceedings of the First Conference of Informing Technology. Krakow, Poland. June, 2001.

Marold, K. , G. Larsen, and A. Moreno. (2002.) Web-Based Learning: Is It Working? A comparison of Student Performance and Achievment In Web-Based Courses and Their In-Classroom Counterparts. Chapter XV of Web Based Instructional Learning. Ed. Mehdi Khosrow-Pour. IRM Press. Hershey, PA.

Marold, K. and R. Socash. (2002.) Experiments with the Interactive "Smart " Classroom. Proceedings of the Annual Meeting of Applied Business Research Conference. Puerto Vallarta, MX. March, 18, 2002.

McCloskey, D. et al. (1998.) Web-Based vs. Traditional Course Deployment: Identifying Differences in User Characteristics and Performance Outcomes. Proceedings of International Business Schools Computing Association Twenty-Sixth Annual Conference. Denver, CO. July 9-11, 1998.

McLuhan, M. (1964.) Understanding Media. NY. McGraw-Hill.

Minsky, M. (1987.) The Society of the Mind. NY. Simon and Shuster.

Negroponte, N. (1995.) Being Digital. NY. Alfred Knopf.

Olson, D. and N. Torrance. (1991.) Literacy and Orality. NY. Cambridge University Press.

Ong, W. (1982.) Orality and Literacy: the Technologizing of the Word. NY. Routledge.

Papert, S. (1980.) Mindstorms: Children, Computers and Powerful Ideas. NY. Basic Books.

Piaget. J. (1977.) The Development of Thought. Translation by Rosin, A. NY. Viking Press.

Presby, L. (2001). Increasing Productivity in Course Delivery. T.H.E. Journal. 28:7. 52-58. 
Schulman, A. and R.I. Sims. (1999.) Learning in an Online Format versus an In-class Format. T.H.E. Journal. 26:11. 54-56. Shank, R. (1995.). Learning and Multimedia Software. Presentation for CASI (Colorado Advanced Software Institute.) US West Advanced Technologies Lab. Boulder, CO. April 12, 1995.

Salomon, G. (1990.) Cognitive Effects with and of Computer Technology. Communication Research. 17:1. 26-44.

Soloway, E. (1995.) Beware Techies Bearing Gifts. Communications of the ACM. 28:1. 17-24.

Turkle, S. (1984.) The Second Self: Computers and the Human Spirit. NY. Simon and Shuster.

Tsichritzis, D. (1999.) ReEngineering the University. Communications of the ACM. 42:6. 93-100.

Vygotsky, L. (1987.) Thinking and Speech: Problem of General Psychology. Vol I. Minick, Morris translation. NY. Plenum Press.

Wolff, J. (1991). Towards a Theory of Cognition and Computing. NY. Ellis Horwood.

\section{Biography}

Kathryn A. Marold is a professor of Computer Information Systems at Metropolitan State College of Denver. She holds a doctorate from the University of Denver, and has published extensively on the areas of electronic communication, multimedia and human-computer interfaces. Her current teaching areas include GUI programming and the development of Web-based courses. Her primary research centers upon the cognitive changes that take place when communicating and learning within an electronic environment. Dr. Marold's website is http://clem.mscd.edu/ maroldk. 